\title{
9 Making our way through the deep waters of life
}

\author{
Music practitioners' professional work in \\ neonatal intensive care units
}

\author{
Taru-Anneli Koivisto
}

\section{Introduction}

In this chapter I discuss the work of music practitioners in neonatal intensive care units, where newborns and their families are in great need of support in the midst of a multi-layered physical, psychological, and emotional crisis. In exploring the expanding professionalism of musicians in various contexts, music practitioners' work in hospitals offers an interesting case. Increasingly often, music practitioners are invited to work with families in hospital wards as part of a comprehensive support effort through music making. When a family enters a neonatal intensive care unit (NICU), whether with a preterm or full-term infant, it is typically due to complications during labour, premature birth, or a severe medical condition in the newborn, meaning that the parents are unable to take care of their child without medical assistance. Within the NICU ward environment these newborns, their families, and healthcare personnel are struggling in life and death situations. In this context, music practitioners contribute to the holistic wellbeing of families rather than exclusively the physical wellbeing of the newborn. Naturally, music practitioners are not expected to be responsible for the health of the individuals, nor is their work necessarily expected to have a measurable impact on their medical health status. Nevertheless, music making may be considered to have a positive impact on the ways in which newborns and their parents experience and sense their overall health and wellbeing.

The work of professional music practitioner in the context of neonatal intensive care must be firmly based on evidence, taking into account what is already known about the significance of music in healthcare in general and music practices in the care of newborns in particular. ${ }^{1}$ A review of earlier research indicates that there is so far fairly limited knowledge or theoretical conceptualisation concerning the work of music practitioners referring to themselves as hospital musicians, healthcare musicians, or health musicians (e.g. Bonde, 2011; Koivisto \& Tähti, 2020; Musique \& Santé, 2019; Ruud, 2012). Recent decades have, however, seen a growing body of music therapy research on the medical care of premature infants (see Loewy et al., 2013; Shoemark \& Dearn, 2016; Van der Heijden et al., 2016). This research has focused on topics such as mother-child bonding, the medically informed use of music, and music psychotherapy. The overall development of 
medical and nursing sciences has transformed NICUs into more parent-friendly and people-centred environments, in which parents are also in current practice encouraged to take care of their infants as much as possible. Cuddling, parental singing, and kangaroo care (skin-to-skin contact) are understood to be highly beneficial for the development of the infant, helping parents to bond with their child (Kaye, 2016; Shoemark \& Dearn, 2016).

Music practitioners - in this case, musicians and other music professionals who work in healthcare contexts - come from a variety of backgrounds, such as performing arts or education. They usually hold an academic degree in music and have attended in-service training in preparation for work in sensitive healthcare environments. ${ }^{2}$ In addition to their work with healthcare and ward personnel, professional music practitioners have begun working in interprofessional settings. These expanding practices require them to acquire a higher level of integrated understanding, such as familiarity with medical practices, principles of patient safety, and trauma-informed care. These new circumstances obviously differ from the more traditional professional spaces of music practitioners. They thereby work in rapidly changing environments where these new settings are not only changing at a rapid pace but are, on a deeper level, constantly being socially re-constructed and understood differently, requiring professionals to adopt novel ethical and relational approaches (Allsup \& Westerlund, 2012; Cribb \& Gewirtz, 2015; Sugrue \& Solbrekke, 2011).

\section{Musicking as a social professional practice in the NICU}

To explore the nature of expanding professionalism for musicians working in the context of healthcare, I use a conceptual lens of "musicking" introduced by Christopher Small $(1987,1998)$ and draw on a qualitative case study that I conducted in a neonatal intensive care hospital unit. According to Small $(1987,1998)$, musicking is a socio-cultural phenomenon and about living and learning in relationships. The core dimensions of musicking - highlighting that music should not be made at people but together with and for them and also emphasising the significance of social dimensions in interpersonal exchange and the aspect that everyone is entitled to musicking - are essential principles for music practitioners in healthcare (Odendaal et al., 2014; Small, 1987, 1998). From the perspective of music practitioners, making musicking possible for all involves harmonising contradictory sets of values, practices, and ways of working in their novel professional approach(es). This approach has been conceptualised as hybrid professionalism by Gielen (2009) and Noordegraaf (2015).

Musicking as the socio-cultural action of making every kind of music with and for people while engaging in relationships with them resonates with the recognition of music making at the NICU ward being "not about me, but about them". This ethically and relationally unsettled and non-traditional professional stance is an essential source of transformative change for the music practitioner's professional identity and practice. Music practitioners at the NICU initiate peoplecentred musicking, which means sharing and taking into account the involved 
families and their emerging emotions in a difficult life situation. Moreover, people-centred musicking involves the healthcare personnel with their duties and working practices. Entering a family room at a NICU ward with shared music making intentions creates new demands for music practitioners and their practices. Their task involves supporting the wellbeing of newborns and their families through singing or playing, but there is also a need for continuous evaluation and decision-making regarding where and when, and what kind of musical choices, instruments, or ways to contribute with music would suit the present circumstances, if at all. In all cases, music practitioners observe and reflect on the situations at hand, mirroring them on their previous knowledge and experiences of music making.

People-centred music making provides opportunities for developing the openness of values, actions, and interactions through musicking (Odendaal et al., 2014, p. 165). Taking into account the emerging emotions of families and the web of relationships at the ward requires moving beyond traditional forms of music and implementing varying and highly relational musicking practices. Adapting one's professional thinking, or that of an entire professional community, does not mean having to work without shared goals or values; however, in the healthcare context, the meanings of the music making arise strictly from the situation at hand and through creating shared meaning in the moment. Moreover, broader understanding of this phenomenon may lead to "changing the professional game" (Bourdieu, $1990,1991)$ in and through the interprofessional collaboration and higher music education more broadly.

\section{Overview of the case study}

In the case study, I observed musicking, that is, social interaction and relationships between a music practitioner and the newborns, their parents, other relatives (such as grandparents), nurses and physicians in the ward lobby, corridors, and patient rooms. ${ }^{3}$ In addition to observing one music practitioner's work, I interviewed two music practitioners, two neonatal nurses, and family members. Through a reflexive (Alvesson \& Sköldberg, 2009) and thematic (Braun \& Clarke, 2006) analysis, I explored the complex ways in which music practices were co-constructed at the NICU ward by music practitioners in collaboration with the families and the hospital staff. Throughout the interviews and observations, metaphors emerged as a way for musicians and members of the hospital community to make sense, construct, and understand meanings of the musicking as well as everyday life in the ward. Therefore, I utilised metaphorical thinking (Lakoff \& Johnson, 1980) as a theoretical tool for analysing the empirical material. While highlighting the hybrid (Gielen, 2009; Noordegraaf, 2015), relational, and transactional nature of musicking in the intensive care of neonates, my guiding questions for the empirical material were:

What kind of musicking emerges when professional music practitioners work in neonatal intensive care units? 
What kinds of metaphors were used by the music practitioners, NICU personnel, and families in their reflections on the musicking situations?

How may these metaphors help to conceptualise music practitioners' professional work in neonatal intensive care units and more broadly in other healthcare contexts?

During the study I have reflected on my own background as a musician, music therapist, and music educator in relation to the professional space and work of music practitioners in the NICU setting. While having been involved in collaborative, intersectoral work in the field of the arts and health for over two decades, I have felt the need to reflect on the implicit, tacit assumptions regarding not only the study participants or the people I work with, but also myself. As a result, my background and experience have helped me to understand the musicking practices and interprofessional thinking examined in this study.

\section{Musicking in a ward environment}

Music practitioners' work in the NICU setting contains the underlying premise, as envisioned by Small (1987, 1998), that everyone, including fragile neonates, has the ability to celebrate life through musicking. Musicking should be open to anyone, and everyone's abilities qualify. Musicking may include performative elements, improvising, sharing emotions and thoughts, as well as listening, observing, and reflecting on the musical entities created together in the situation at hand. When encountering families in a vulnerable position, musicking as a way to celebrate everyday ward life is a way for music practitioners to emphasise that "all musicking is serious musicking" (Small, 1998, p. 222). The notion that everyone is able to engage with music, and that no music or way of musicking is "intrinsically better than any other" (p. 222) makes music available to all families and healthcare personnel at the ward. Beyond the individual rooms, musicking takes place in the whole ward environment: corridors, nurse stations, halls, and entrances. With this in mind, the music practitioner has to be capable of managing the administration, planning, and organisation of music making in the neonatal ward. Within this study, five kinds of musicking situations were identified when the people in the ward engaged in music making. These situations did, of course, display a significant degree of hybridity but can be subdivided into the following categories:

1. Musicking solely with and for the newborn. Very simple, smooth, and tranquil, even sedative music was utilised in these situations, such as improvising a lullaby or modifying various kinds of traditional music. An appropriate situation for the music might be, for example, when the newborn was waking up, or during nursing or treatment. Using both sound and silence, as if they were a light and a shadow playing together, was seen as important when intertwining the music with the newborn's experiences and sensations of the world. If the infant was sound asleep — which is a crucial element of healing 
between the continuous care procedures and their frequent interruptions - the music practitioner moved to another room.

2. Musicking during the therapeutic or care procedure. When it was decided to bring music into the room where some procedures were taking place, the music practitioner often started the musicking by probing the atmosphere, for example, by playing just a few strings from a Finnish kantele and/or humming in hardly audible, low tones. This situation might take place, for example, within therapeutic or care procedures, or when feeding the child. Sometimes there could even be a small surgical procedure taking place, but this was not necessarily considered "everyday practice" for the music practitioner. Parents and/or a nurse were listening while taking care of the baby as gently as possible. Parents sometimes joined in the singing or had a request for a particular song. The atmosphere in the room was generally drowsy, and the only sounds were the music and the beeps and alarms of the monitors.

3. Musicking with and for the family. When the families were not in a hurry and felt that they were willing and that the time was appropriate, many kinds of musicking - humming, singing, improvising, listening - and reflecting could take place. Either one or both parents, and occasionally one or more nurses, could join this moment. Sometimes the mother would simultaneously prepare breast milk for the child. Many times, when the mother was otherwise occupied or resting, the father took the newborn to his chest and sang for, cuddled, and stroked his child gently.

4. Musicking with and for an extended group. This collaboration could take many forms: a small performative kind of moment, relaxation through listening, experiencing music holistically, or reflecting intergenerational memories through music. Emotions could change dramatically within the music making. Relatives or friends could be included, and a grandparent could either simply observe the shared music making or actively join the musicking by playing an instrument or singing, narrating his or her own memories or the situation at hand.

5. Musicking with and for the hospital personnel. The tone of soft chimes, harp, sansula, or vocal sounds echoing in the ward environment also touched the healthcare professionals. For the hospital personnel the moments of live music were brief moments of rest, where they could take a break from the hectic rhythm of the working day. Musicking with and for the personnel was not an isolated situation in a separate place that could be focused on them alone, but calming moments during their shift. For the personnel in this study, musicking together was primarily co-constructive participation, reflection, interprofessional observation, and about receiving information during the musicking situations, rather than active musicking with the others.

These categories illustrate how the conceptual lens of musicking allows the understanding of music professionalism in a healthcare setting as a social phenomenon more complex in nature than traditional views of music professionalism might suggest. Consequently, music practitioners may reach a point where 
their own fundamental values are challenged, and they begin asking what kind of core values underlie their practices. In the everyday work of music practitioners, this means that an understanding of the importance of situational ethics becomes crucial and a "constant re-organization of values for the good or the growth of oneself and other" takes place (Allsup \& Westerlund, 2012, p. 126). This entails a professional maturity, which can be called professional altruism; the will to see working with other professions as a fruitful collaboration instead of a threat to or problem for one's own professional existence (Axelsson \& Axelsson, 2009). This kind of professional transformation stems from the development of professional fields overall (Cribb \& Gewirtz, 2015; Sugrue \& Solbrekke, 2011).

Although the music practitioners examined in the study could be considered to be at the fringe of the healthcare hierarchy, musicking was consistently seen as a highlight of the ward life by those working there regularly. The nurses made an effort to open up space for the music practitioners' work and musicking in the ward so as to give as many families and newborns the opportunity to participate. Finding a way towards more sustainable practice through continuity of musicking was stressed as a very urgent issue by all of the participants interviewed, but there were hardly any tools - such as time for interprofessional development processes, economic resources, or organisational aims and strategies - available to put the music practitioners' work in the ward on a systematic footing.

\section{Reflective music practitioners in the ward: Four grounding metaphors}

Exploring new ways of thinking about one's profession, such as music making, speaking, and what I call expressing narratives through metaphors, requires sensitivity and negotiation. This sensitivity seemed to help music practitioners in engaging the interprofessional setting and discovering how their musicking practices and musicianship were related to the situations of the families in a meaningful and relevant way. In the content analysis of the interview material I noticed that the participants used metaphors in their reflections on the musicking in the healthcare unit. Although their speech was vernacular, they made use of metaphors to emphasise their experiences. Metaphorical thinking thus became central to understanding the phenomenon.

Four grounding metaphors were identified from the empirical material and shaped through my reflexive analysis, bridging musicking and life in the ward together. According to Lakoff and Johnson (1980), metaphors allow a domain of experience to be understood through other concrete, understandable terms. The emerging metaphors were reflected from different viewpoints: considering the sensitivity music practitioners should have when reflecting on their work before, during, and after the musicking takes place; navigating with musical practices through different situations in the ward; and in relation to future opportunities to develop the work of professional music practitioners. Experiencing, speaking, and learning through metaphors may be thought of as an unfeigned production of human nature. A metaphor is neither a "true" nature nor a factual truth about 
aspects in the world, but it is not purely symbolic, either. Rather, it is our way to conceptualise, experience, or comprise the world (Lakoff \& Johnson, 1980). In the context of my study, metaphors helped the music practitioners and healthcare professionals crystallise the implicit thoughts and knowledge held by themselves and the families they worked with in the ward.

\section{Metaphor 1: Earthquake}

The context of the study was underpinned by the understanding that the families were going through chaotic and conflicting experiences. Simultaneously, the healthcare professionals and music practitioners were concentrating on handling the different situations in the ward in an ethical, practical and professional way. Described through the metaphor of an earthquake, the state of affairs was shaking the basis and solidity of the various families. The parents' ideas of parenthood and their baby's early childhood may have been shattered, and much of their time was likely to revolve around the neonatal unit and its routines and procedures within the hospital. The parents could be reconstructing the collapsed dreams and visions of family life: "Well, it isn't a place for a child or family to be in an intensive care unit, and the parents' special thoughts about parenthood and that baby time have collapsed, and one has to build a kind of new life and start anew" (neonatal nurse). Similarly, the parents could be wrestling with their fear of the child's death, their fear of the baby having a severe disability, or the situation after what had been considered a difficult delivery.

In these kinds of situations, any possible interruption of the ward atmosphere by the music practitioner was considered not only as a priority for the child but also for the family. Parenthood, the role of parent(s), was described as very limited in the flux of the ward, though the policies of the ward were considered very modern, with kangaroo care, supporting parenthood where possible, and seeking to endorse the individual situations of families. In the musicking situations, tears would often burst from the eyes of the adults in the families. These events with the music practitioner were seen as an opportunity for the parents to see their newborn child through the musicking as 'just a child', clearly and completely, without inhospitable medical interventions and devices:

In a way it kindles such a connection and intimate moment [when musicking together], that the parents see their child without any hospital equipment, any meters, even if there were alarms ringing, or the child would be in a ventilator, or whether they would have any kind of medical infusion going on at the same time - in that situation they are somehow able to just see their own baby, and it is a very irreplaceable moment.

(Neonatal nurse)

\section{Metaphor 2: Deep waters}

Some families perceived music as something that takes them through "deep waters". This metaphor mirrored their times of great difficulty and inability to 
resolve the challenges ahead on their own. The interviewed parents felt that musicking contributed to the wellbeing of the families, and it was interpreted as a sign of life from the outside world, allowing them to comprehend that even in hard times life will carry on. This hope, and processing the experience of parenthood, were seen as important benefits of providing the families with music making, although the risk of going too far was also recognised: "Sometimes I am thinking whether we are going into too deep waters. But instead, every time I have seen only positive impacts, and parents have been brought closer to the baby or given an opportunity to process difficult feelings or issues pertaining to their parenthood" (neonatal nurse). Musicking in these deep waters could give parents, or a single parent, an opportunity to reflect on the life situation they were now in as a family:

Then the mother asked [the grandmother of the baby] if she had requested from the music practitioner too sensitive a song, and her mother said that no, that is a fine song. Then we sang it together, and the grandmother started crying overwhelmingly. Afterwards she went to blow her nose and wash, but the mother [of the baby] was all the time, in a way, very happy.

(Music practitioner)

\section{Metaphor 3: Flow of flux}

The experience of time and space in the NICU ward was described by the metaphor of flow, where time flowed in waves or pulses, in an ever-changing way, and differently from everyday life outside the ward. Within this flow, the families were facing continuous change and innumerable shades of anxiety relating to the health of their baby. Additionally, their daily schedules, as well as future plans, were in a constant state of flux. Within the timescape of the ward, music was included as a soft, integral element, sensitively modifying the ward atmosphere between its smooth and cottony and, to some degree, more energetic moments. The combination of the fragility of the newborns, the concerns, fears, and hidden anxieties of the parents, and the sensitive music making of the music practitioner created sensations of pausing, where time seemed to stop. Words were not necessarily needed: "When the music practitioner enters into the situation, she takes us momentarily to another place. And it is quite exciting to see how everything, in a way, comes to a halt at that moment. In that situation, words could have ruined a lot" (neonatal nurse).

Taking into account the transitions between life and death was one of the most important dimensions of the music practices implemented by the music practitioners. Within the overall flow of the ward, a music practitioner could be attending to various kinds of situations, and urgent attention was sometimes required in the case of dire events, as in the case of the death of a newborn. The moments of grief and loss could come as abruptly as any other situation in the ward:

Once, there were two babies [from different families] in the room. One of the babies had just died. And there was a nurse beside her. I noticed that she was in sorrow. Of course it touches you. Just a moment ago I was asking myself, 
what could I do now for them. But then, I decided first to sing for that nurse to support her [and then turned to sing for the other baby].

(Music practitioner)

Such examples were also used by the interviewed music practitioners when reflecting on whether the work would be suitable for everyone. Though the work was seen as unique, meaningful, and momentous, in turn it may be revealed as sometimes being quite miserable as it exposes scenes of life that one may have trouble coping with. The musical flow in the ward also included reflections on how the professional awareness of the personnel affected the soundscapes and the vocal sound environment as a whole.

\section{Metaphor 4: A path and a journey}

The image of music professionals travelling alongside the families was apparent throughout the research data, and many families wanted to share these moments with the healthcare personnel and music practitioners, observing and reflecting on the reactions of their babies together with them. The music practitioners' journey with the infant was seen as special and important:

Labour had been hard and heavy. The mother of the baby was a few floors above, and reportedly in very much pain in her back. But the father was at the musicking moment, behaving in a completely beautiful manner with that baby ... Then he had to go and see his wife. He asked if I could stay for a little while to sing for his baby, so that she would not be left alone.

(Music practitioner)

The challenging situation influences the lives of whole families; something in the lives of these people has changed forever, permanently, and the family will now go on to another place along this path. The musical event was depicted as an interruption, allowing the whole family to metaphorically travel to another space or place. When taking a musicking journey together, music may help the family members create a novel narrative of their life. This kind of shared event was also described as highly intimate and sensitive for the personnel and the music practitioners. Apart from the metaphorical journey of the families, the metaphor of professional music work as a pathway with many bends was continuously raised; this path opens up the possibility for professional change and transformation in a meaningful manner.

\section{Ethical considerations}

The case study I have presented in this chapter brings into focus some of the ethical and moral challenges of musicking in hospitals and other healthcare contexts. For music practitioners in healthcare, relational and situational music work means moving beyond fixed musical spaces and approaches towards more flexible, hybrid ways of working with music and people, as Gielen (2009) and 
Noordegraaf (2015) have suggested. Noordegraaf presents hybrid professionals as being "likely to have the capacity to bridge divergent logics" $(2015$, p. 8$)$ within their organisations. This means that hybrid music practitioners are moving towards independent ways of planning, reflecting on, and managing music making within the ward. What becomes essential is a conscious turn towards reflexivity and relational ethics, or, as proposed by Allsup and Westerlund (2012), situational ethics. Noordegraaf (2015) states that we should even go beyond this kind of hybridisation, and see professionalisation as reflexive in such a way that hybridity and its dimensions of managing professional spaces would form a normal part of future work. For example, encountering the world of sorrow and grief in relevant ways - and at the same time, being peaceful and full of hope - helps music practitioners interact with families and the whole ward community, as well as to reorganise their practice in these ethically challenging and situational processes. This is one of the main reasons why the education and knowledge of music practitioners' expanding professionalism and hybrid work in healthcare and other intersectoral contexts need to be developed further.

According to Gielen (2009), every kind of hybridity may also function as a hinder in artists' professional lives, excessively shaping their professional identities and working contexts. In music practitioners' work, this means that the hybrid nature of the profession is unnecessarily dominant; music professionals' ethical positioning, their music practices, and the relationships they create in their work become impossible to manage, which may be troubling and demotivating. In order to prevent this, future music practitioners must articulate and open up about their transforming positions and practices in society on an interprofessional basis. It can, therefore, be argued that an expanding, hybrid professionalism should be recognised in higher music education, acknowledging the transformation and change of artists' positions in societies.

\section{Conclusion}

The metaphors described in this article illustrate the nature of expanding professionalism for musicians working in new, specific healthcare contexts, simultaneously creating "new rules for the game" (Bourdieu, 1990, 1991) in the professional field of musicians and artists. Exploring the hybrid practices through metaphorical language and thinking (Lakoff \& Johnson, 1980) helps to understand how music practitioners simultaneously expand their professional space and music practices in a hospital ward through co-constructing interprofessional work and (re-)creating people-centred musicking together with the hospital community. Metaphors may help musicians and artists in new work environments in at least two ways: firstly, by creating mutual understanding in interprofessional communities. Music practitioners use interprofessional language that emerges through their musicking practices to build and bridge relationships with the families and the hospital ward community. Using metaphors helps music practitioners to engage in the interprofessional work and practices in healthcare environments with other professionals. Secondly, using metaphors helps music practitioners to settle in the ever-changing time and space of the healthcare environment to foster mutual trust 
and accountability in their collaboration with healthcare professionals, and to justify the relatively high degree of professional autonomy that is appreciated in and required from music practitioners working at the ward.

To understand the practices, rules, and requirements - the doxa (Bourdieu, 1990, 1991) of a new field - music practitioners have to engage not only in interdisciplinary learning in their own institutions but also, more broadly, in the interprofessional sharing of knowledge. In order to enter novel social and cultural spaces successfully, individual music practitioners are obliged to recognise and embed some of the core principles of such new contexts in their work. In addition, they have to be capable of engaging with the people in the ward in a musically adequate manner, which also must take an ethically relevant and suitable form. They must then situate their practice in relation to the fundamental issues and principles in the ward, such as supporting the wellbeing of families and babies with musicking, understanding the highly relational and reflexive nature of music practices in different care situations, or acting professionally when healthcare personnel must carry out medical procedures. Crystallising the implicit, tact, and embodied thoughts and knowledge, using appropriate language when speaking to other professionals and the families, and situating the musicking practices and one's musicianship in a meaningful and relevant way in the ward environment becomes the focus of music practitioners' work.

Metaphorical thinking may be one way to navigate, develop, and co-construct interprofessional work in complex healthcare contexts, as well as to break down the boundaries of expertise professionalism in which music and musical quality are predominant values. Metaphorical thinking helps music practitioners to identify musicking in healthcare as a wider phenomenon in relation to understanding and communicating music as a public service, freely available to all. New musical elements have a variety of impacts on the hospital ward environment. The music practitioners themselves create new ways of thinking and acting by musicking in a NICU environment in a way that goes beyond their customary practices of performing, teaching, and playing musical pieces together. In the professional spaces that thus open up for them, which hold a very different logic of action from what music practitioners are accustomed to, music practitioners must have a particular sensitivity and awareness regarding close relationships with families, nurses, and other people within the ward environment. In addition to helping identify the socio-cultural benefits of musicking beyond the technical aspects of traditionally skilled music making, metaphors may also help music practitioners to engage emotionally in the diverse situations in which families find themselves. Most importantly, the emotional and relational engagement of music practitioners may help families explore their emotionally unique situation: the birth of a child in a medicalised and difficult environment.

Experiencing, speaking, and learning through metaphors may be a valuable asset for music practitioners, providing ways to bridge music practices with the time and space in the ward, but also to engage with their own expertise and existing professional identity. Furthermore, bridging emotional experiences and metaphorical language in musicking with families, as well as finding and celebrating the brief, precious moments of shared wellbeing, may integrate the hospital ward 
socially in such a way that the families and their challenging situations are supported in a relevant manner. Co-constructing metaphors through musicking makes ethical and moral challenges more visible, highlighting their overall importance and the meaningfulness of music practitioners' work. This does not instrumentalise music or music practitioners' work, but rather expands their professionalism in a flexible manner. It also suggests novel directions for the development of higher music education in the future.

\section{Call for action: Building the futures of expanding music professionalism through higher music education}

As a final thought, I will briefly reflect on some misconceptions in the work of music practitioners in somatic healthcare. These misconceptions also appeared in the case study presented here, highlighting the importance of taking them into consideration when organising higher music education in the future (see also Koivisto \& Tähti, 2020). (1) Although music practitioners are often seen to bring joy and energy to the people in the hospital wards while engaging and empowering both patients and healthcare professionals to consider their own wellbeing, broader contexts of social justice, rehabilitation, and cultural rights are not yet widely recognised in practice, academic research, or the professional education of music practitioners. (2) Although the music practitioners usually see their work as highly rewarding and important in healthcare, the fragmented nature of the work creates challenges in handling the workload and may produce overwhelming emotional burdens for music practitioners. This requires reforms in higher education as well as in the institutions where music practitioners will work. (3) Although music practitioners are increasingly welcome to work in healthcare settings and learn "on-the-job", higher music education students should be equipped through educational solutions with proper professional understandings of how to work in socially and ethically hybrid and unsettled contexts, surrounded by everchanging relationships and processes. This should include resolving issues such as gatekeeping practices of healthcare systems, professional and organisational boundaries, and appropriate musicking practices in the ward environment.

In conclusion, music students in higher education would benefit from acquiring and developing relational and metaphoric interprofessional thinking to reach beyond established musical performance practices and traditions. This positive and fruitful type of hybridity could be achieved by increasing interprofessional collaboration in higher music education and by engaging in work between organisations in different fields.

\section{Acknowledgements}

This work was supported by the ArtsEqual project, funded by the Academy of Finland's Strategic Research Council from its Equality in Society programme under Grant [number 314223/2017]. 


\section{Notes}

1 Expanding practices requires broad understanding. For example, some hold the view that music can be detrimental to the premature infant's development (see Standley, 2003) through neurological overstimulation or exceeding sound level recommendations. It is therefore crucial that the education and professional knowledge of music practitioners is evidence-based when entering these fragile environments.

2 In this chapter, a music practitioner is a professional holding an academic degree in music. He or she may be a music educator, a musician with a background in folk, jazz, or classical music, or an ethnomusicologist. Their practices often seem to be intertwined with a variety of professional approaches, and music practitioners may not necessarily identify themselves a priori as, for example, pedagogues or musicians, but refer to themselves as representing both professional categories. Thus, they are not music therapists, having their own professional niche in hospitals or being understood as healthcare professionals bound by laws and regulations when providing healthcare services.

3 A research permit for the study was granted by the hospital district in 2018, and an ethical statement from the Research Ethics Committee of the University of the Arts Helsinki was also submitted.

\section{References}

Allsup, R. E., \& Westerlund, H. (2012). Methods and situational ethics in music education. Action, Criticism, and Theory for Music Education, 11(1), 124-148.

Alvesson, M., \& Sköldberg, K. (2009). Reflexive methodology: New vistas for qualitative research. Sage.

Axelsson, S. B., \& Axelsson, R. (2009). From territoriality to altruism in interprofessional collaboration and leadership. Journal of Interprofessional Care, 23(4), 320-330. doi:10.1080/13561820902921811

Bonde, L. O. (2011). Health musicing — music therapy or music and health? A model, empirical examples and personal reflections. Music and Arts in Action, 3(2), 12-140.

Bourdieu, P. (1990). The logic of practice. Polity Press.

Bourdieu, P. (1991). Language and symbolic power. Polity Press.

Braun, V., \& Clarke, V. (2006). Using thematic analysis in psychology. Qualitative Research in Psychology, 3(2), 77-101. doi:10.1191/1478088706qp063oa

Cribb, A., \& Gewirtz, A. (Eds.). (2015). Professionalism. Polity Press.

Gielen, P. (2009). The murmuring of the artistic multitude: Global art, memory and postFordism. Valiz.

Kaye, S. (2016). Historical trends in neonatal nursing. The Journal of Perinatal \& Neonatal Nursing, 30(3), 273-276. doi:10.1097/JPN.0000000000000200

Koivisto, T.-A., \& Tähti, T. (2020). Professional entanglements: A qualitative systematic review of healthcare musicians' work in somatic hospital wards. Nordic Journal of Music Therapy, 28(5), 416-426. doi:10.1080/08098131.2020.1768580

Lakoff, G., \& Johnson, M. (1980). Metaphors we live by. The University of Chicago Press.

Loewy, J., Stewart, K., Dassler, A. M., Telsey, A., \& Homel, P. (2013). The effects of music therapy on vital signs, feeding, and sleep in premature infants. Pediatrics, 131(5), 902-918.

Musique \& Santé. (2019, December). Advocating and working for the development of live music in hospitals and institutions for disabled persons. http://www.musique-sante.org /en 


\section{Taru-Anneli Koivisto}

Noordegraaf, M. (2015). Hybrid professionalism and beyond: (New) forms of public professionalism in changing organizational and societal contexts. Journal of Professions and Organizations, 2(2), 187-206. doi:10.1093/jpo/jov002

Odendaal, A., Kankkunen, O. T., Nikkanen, H. M., \& Väkevä, L. (2014). What's with the $\mathrm{K}$ ? Exploring the implications of Christopher Small's 'musicking' for general music education. Music Education Research, 16(2), 162-175. doi:10.1080/14613808.2013. 859661

Ruud, E. (2012). The new health musicians. In R. A. R. MacDonald., G. Kreutz, \& L. Mitchell, (Eds.), Music, health and wellbeing (pp. 76-87). Oxford University Press.

Shoemark, H., \& Dearn, T. (2016). Music therapy in the medical care of infants. In J. Edwards (Ed.), The Oxford handbook of music therapy (pp. 24-52). Oxford University Press.

Small, C. (1987). Musicking - The means of performing and listening. Wesleyan University Press.

Small, C. (1998). Music of the common tongue: Survival and celebration in African American music. Wesleyan University Press.

Standley, J. M. (2003). Music therapy with premature infants: Research and developmental interventions. The American Music Therapy Association.

Sugrue, C., \& Solbrekke, T. D. (Eds.). (2014). Professional responsibility: New horizons of praxis. Routledge.

Van Der Heijden, M. J. E., Araghi, S. O., Jeekel, J., Reiss, I. K., Hunink, M. M., \& Van Dijk, M. (2016). Do hospitalized premature infants benefit from music interventions? A systematic review of randomized controlled trials. Plos One, 11(9), e0161848. 